\title{
BMJ Open 'A silent epidemic of grief': a survey of bereavement care provision in the UK and Ireland during the COVID-19 pandemic
}

\author{
Caroline Pearce (D) , ${ }^{1}$ Jonathan R Honey, ${ }^{2}$ Roberta Lovick, ${ }^{1}$ \\ Nicola Zapiain Creamer, ${ }^{3}$ Claire Henry, ${ }^{1}$ Andy Langford, ${ }^{4}$ Mark Stobert, ${ }^{5}$ \\ Stephen Barclay ${ }^{1,2}$
}

To cite: Pearce C, Honey JR, Lovick $\mathrm{R}$, et al. 'A silent epidemic of grief': a survey of bereavement care provision in the UK and Ireland during the COVID-19 pandemic. BMJ Open 2021;11:e046872. doi:10.1136/ bmjopen-2020-046872

- Prepublication history and supplemental material for this paper is available online. To view these files, please visit the journal online (http://dx.doi. org/10.1136/bmjopen-2020046872).

Received 16 November 2020 Revised 20 January 2021 Accepted 10 February 2021

Check for updates

(C) Author(s) (or their employer(s)) 2021. Re-use permitted under CC BY-NC. No commercial re-use. See rights and permissions. Published by BMJ.

${ }^{1}$ Primary Care Unit, Department of Public Health and Primary Care, University of Cambridge, Cambridge, UK

${ }^{2}$ School of Clinical Medicine, University of Cambridge,

Cambridge, UK

${ }^{3}$ Arthur Rank Hospice,

Cambridge, UK

${ }^{4}$ Cruse Bereavement Care,

Richmond, UK

${ }^{5}$ Addenbrooke's Hospital, Cambridge, UK

Correspondence to

Dr Caroline Pearce;

cmp89@medschl.cam.ac.uk

\section{ABSTRACT}

Objectives To investigate the experiences and views of practitioners in the UK and Ireland concerning changes in bereavement care during the COVID-19 pandemic.

Design Online survey using a snowball sampling approach.

Setting Practitioners working in hospitals, hospices, care homes and community settings across the UK and Ireland.

Participants Health and social care professionals involved in bereavement support.

Interventions Brief online survey distributed widely across health and social care organisations.

Results 805 respondents working in hospice, community, and hospital settings across the UK and Ireland completed the survey between 3 August and 4 September 2020. Changes to bereavement care practice were reported in: the use of telephone, video and other forms of remote support (90\%); supporting people bereaved from nonCOVID conditions (76\%), from COVID-19 (65\%) and people bereaved before the pandemic $(61 \%)$; funeral arrangements (61\%); identifying bereaved people who might need support (56\%); managing complex forms of grief (48\%) and access to specialist services (41\%). Freetext responses demonstrated the complexities and scale of the impact on health and social care services, practitioners and their relationships with bereaved families, and on bereaved people.

Conclusions The pandemic has created major challenges for the support of bereaved people: increased needs for bereavement care, transition to remote forms of support and the stresses experienced by practitioners, among others. The extent to which services are able to adapt, meet the escalating level of need and help to prevent a 'tsunami of grief' remains to be seen. The pandemic has highlighted the need for bereavement care to be considered an integral part of health and social care provision.

\section{INTRODUCTION}

Bereavement care is a significant component of the work of a wide range of health and social care professionals, yet it is often unrecognised and considered a low priority in healthcare policy and practice. The global COVID-19 pandemic has brought to the fore the importance of end-of-life and bereavement care. The

\section{Strengths and limitations of this study}

- This national survey of health and social care professionals is the first to identify the major impact of the pandemic on bereavement care in the UK

- Eight hundred and five responses from across the UK and Ireland were received from a wide range of professional roles and settings.

- Due to the snowball sampling approach, it is not possible to calculate a response rate.

- While there was consistency in responses across settings, further research is needed to investigate the settings and bereaved populations where support needs are highest.

scale of the impact of the COVID-19 pandemic on those bereaved is now becoming apparent: it is estimated that for every COVID-19 death, nine people are affected by bereavement. ${ }^{1}$ Deaths from COVID-19 are characterised by factors that may increase the risk of complicated and prolonged grief responses ${ }^{2-4}$ including: sudden and unexpected deaths, deaths in intensive care units, patient isolation and severe symptoms including breathlessness at the end of life..$^{5-8}$ Social distancing measures have had a major impact on those bereaved from all causes, not only from COVID-19. These essential measures restricted visiting in hospitals, care homes and hospices, preventing loved ones saying goodbye and leaving some to die alone. Viewing the deceased person's body and funeral proceedings were severely curtailed. Bereaved people may feel especially isolated and unable to access the benefits of social support. ${ }^{9}$ People bereaved prior to the pandemic are also affected, with social isolation and interrupted bereavement care intensifying feelings of grief. ${ }^{10}$

Evidence is limited on the ways in which the pandemic is impacting on the experience of bereavement. A review found that pandemics may cause multiple losses, both directly related to the death itself and symbolic losses 
to individual and societal bereavement practices. ${ }^{11}$ Rituals related to the management and disposal of bodies have significance across a range of religious and cultural communities and the disruptions caused by pandemics may impact bereavement outcomes. ${ }^{12-14}$ Harrop et $a l^{15}$ reviewed the evidence regarding system-level responses to mass bereavement events, including natural and humanmade disasters as well as pandemics. The authors found limited research of low quality, but identified several consistent messages for improving bereavement support provision during and after the pandemic including adopting a proactive support model, central coordination of locally delivered services and training in core competencies specific to COVID-19 for those delivering support.

At present, however, it is not clear what forms of support are appropriate or effective during and following pandemics. ${ }^{16}$ To support practitioners and policymakers, we surveyed practitioners in the UK and Ireland concerning changes in their bereavement care practice, including the target group, mode and content of delivery during the COVID-19 pandemic.

\section{METHODS}

A descriptive cross-sectional online survey (see online supplemental appendix 1) was developed in Survey Monkey. Initial development of survey was carried out by CP and SB, following consultation with a patient and public involvement (PPI) group (detailed below) and discussions with stakeholders including hospice and hospital chaplaincy staff. The study was developed in parallel with a literature review of bereavement care, which had provided the team with up-todate knowledge of the evidence base and an established network of stakeholders. All authors contributed to the development of the survey drawing on their clinical, research and lived experience in bereavement care, respectively. Literature concerning the potential impact of COVID-19 on bereavement care also informed the content of the survey questions. ${ }^{2-46-81115}$

\section{Patient and public involvement}

The Cambridge Palliative and End of Life Care PPI group were involved throughout the development, dissemination and analysis of the survey. Following a meeting in April 2020 where priority areas for bereavement research were discussed, RL joined the project advisory group to ensure that PPI perspectives were included throughout, especially development of the survey instrument. A second PPI group meeting in September 2020 discussed the survey findings, identified key recommendations for practice, advised concerning dissemination strategy and suggested avenues for further research.

\section{Study procedure}

Health and social care organisations based in the UK were approached based on their professional involvement in supporting bereaved people. After a local pilot involving three respondents, the following organisations distributed an email with the survey link between 3 August and 4 September 2020 to their members and/or professional networks via email lists, member newsletters and/or social media: Association for Palliative Medicine of Great Britain and Ireland, UK Queen's Nursing Institute, Royal College of General Practitioners, Hospice UK, National Association of Funeral Directors, National Bereavement Alliance, Association of Hospice and Palliative Care Chaplains, UK Board of Health Care Chaplains, College of Health Care Chaplaincy, Dying Matters, Association of Directors of Adult Social Services in England, Care Association Alliance, National Care Association, Care Provider Alliance, The Cremation Society, British Psychological Society and a national network of PPI leads.

Participants were encouraged to forward the survey link to interested colleagues, seeking a snowball sample of practitioners.

Responses were anonymous unless respondents supplied their name and email address in the optional final field to indicate interest in further research. After initial questions seeking demographic data concerning respondents' geographical areas of work, professional roles, work settings and involvement in bereavement care, the main question addressed changes in bereavement care practice (if any) during the COVID-19 pandemic. These included identifying bereaved people who might need support, restrictions regarding funeral arrangements, supporting people bereaved from COVID-19 and from non-COVID-19 conditions, supporting people bereaved before the pandemic, managing complex forms of grief, use of telephone, video or other remote support, and access to specialist services for the bereaved. Details regarding changes in practice were invited in free text. A final optional question invited further comments on supporting bereaved people during the pandemic.

\section{Data analysis}

The Checklist for Reporting Results of Internet E-Surveys was followed. ${ }^{17}$ Descriptive statistics were used for demographic and categorical response data. Analysis of freetext replies was undertaken by CP and JRH. Following a thematic analysis approach, themes were developed inductively from the data by coding responses and allocating them to thematic categories. ${ }^{18} \mathrm{CP}$ conducted preliminary coding of the free-text data and developed an initial coding structure which categorised codes into overarching themes. A second author (JRH) independently analysed a proportion $(25 \%)$ of the free-text responses using the initial coding structure, allocating quotes to the relevant theme. The coding framework was then revised in an iterative process through discussions with SB, until consensus on the final themes was reached.

\section{RESULTS}

\section{Respondents}

Eight hundred and five survey responses were received between 3 August and 4 September 2020 from a wide 


\begin{tabular}{|c|c|}
\hline Professional role & No of respondents \\
\hline Nurse & $176(22 \%)$ \\
\hline Palliative care specialist nurse & 103 \\
\hline Community nurse & 51 \\
\hline Other nurse & 22 \\
\hline $\begin{array}{l}\text { Bereavement counsellor, support } \\
\text { worker or volunteer }\end{array}$ & $173(21 \%)$ \\
\hline Chaplain & $115(14 \%)$ \\
\hline Doctor & $98(12 \%)$ \\
\hline Palliative care doctor & 65 \\
\hline General practitioner & 28 \\
\hline Other doctor & 5 \\
\hline Health and social care management & $54(7 \%)$ \\
\hline Social worker/social care worker & $52(6 \%)$ \\
\hline Allied health professionals & $35(4 \%)$ \\
\hline $\begin{array}{l}\text { Psychologists, psychotherapists } \\
\text { and counsellors }\end{array}$ & $30(4 \%)$ \\
\hline $\begin{array}{l}\text { Bereavement service manager or } \\
\text { coordinator }\end{array}$ & $29(4 \%)$ \\
\hline Administration & $27(3 \%)$ \\
\hline Funeral director/celebrant & $19(2 \%)$ \\
\hline Total & $\begin{array}{l}808 \text { (three respondents } \\
\text { identified two job roles) }\end{array}$ \\
\hline
\end{tabular}

range of health, social care and bereavement professionals (table 1 ).

Responses were received from across the UK and Ireland (figure 1) from practitioners working in hospice (37\%), primary care and community (32\%), hospital (25\%) and care home $(6 \%)$ settings. Participants were involved in a range of bereavement care provision: emotional support and listening $(88 \%)$, pre-bereavement support prior to death $(72 \%)$, support immediately after a death $(72 \%)$, providing information on support services $(65 \%)$, referring for specialist support (51\%), bereavement counselling $(40 \%)$, clinical assessment of support needs (38\%), practical arrangements of certificates and funerals (34\%), prescribing medication $(11 \%)$ and specialist psychological/psychiatric support (10\%).

\section{Changes in bereavement care practice}

Respondents reported major changes in their personal provision of bereavement care and/or changes in their area across all the listed categories. These changes are presented in table 2, along with examples from the thematic analysis of the explanatory free text.

The greatest change to bereavement support was in the mode of delivery and the use of telephone, video and other forms of remote support, reported by $90 \%$ of respondents. Prior to the pandemic, telephone and video had been used rarely but were now the primary mode of support.
Practitioners reported changes in skills required to support people bereaved by non-COVID-19 conditions (76\%) and COVID-19 (65\%). Support for people bereaved before the pandemic also experienced significant change $(61 \%)$ as many bereavement services had been suspended and/or had shifted to online or telephone formats.

Regardless of cause of death, it was emphasised that the support provided was largely consistent, as all families had experienced similar restrictions prior to and after a death. Frequently reported were the impact of restrictions on funeral arrangements $(61 \%)$, and reduced opportunities for in-person interaction also produced difficulties when identifying bereaved people who might need support (56\%).

Less changes in managing complex forms of grief (48\%) and access to specialist services (41\%) were reported, although many were unsure of changes in these areas.

\section{Impacts on bereavement care practice: analysis of free-text responses}

A total of 3543 free-text comments were received in response to Q5 and Q6. Analysis of respondents' freetext comments identified three key areas impacted by the pandemic: health and social care services; clinicians and their relationships with bereaved families; and bereaved peoples' experience. These are explained below with illustrative quotes: further detail is shown in table 3 .

\section{The impact on health and social care services}

Services faced initial challenges adapting to changing national government guidelines. Some bereavement services were suspended due to staff being furloughed or redeployed, particularly specialist services. Volunteer support in hospitals and hospices was reduced due to visiting restrictions. Associated with an increase in deaths, for some services this led to increased waiting lists: 'We had $600 \%$ increase in deaths for a 3-week period. Dealing with the backlog of bereavement support was challenging' (\#15 palliative medicine doctor).

Bereavement care fell to a wide range of staff members, including some with limited experience of or training in supporting bereaved people who had to rapidly develop the required communication skills: 'Doctors, in particular F1 and F2, have really developed... bereavement skills' (\#66 end of life advanced nurse practitioner).

Some reported that prior insufficient existing resources created even greater challenges, with concern that the pandemic would worsen the situation and add new difficulties due to the complex grief reactions: 'We didn't have a sufficient bereavement service pre covid' (\#512 nurse).

Adapting care to online or telephone formats was particularly challenging with limited access to the equipment needed and staff training to use them: 'Staff didn't know about them, hadn't been shown how to use them, which apps to use and how to log in' (\#74 palliative medicine doctor). Changes were needed to governance processes and confidentiality agreements to accommodate the 


\begin{tabular}{|l|l|}
\hline Geographical location & $\mathbf{N}$ \\
\hline East of England & 99 \\
\hline London & 101 \\
\hline Midlands & 150 \\
\hline North East and Yorkshire & 76 \\
\hline North West & 84 \\
\hline South East & 134 \\
\hline South West & 93 \\
\hline Scotland & 32 \\
\hline Wales & 12 \\
\hline Northern Ireland & 10 \\
\hline Channel Islands & 4 \\
\hline Republic of Ireland & 5 \\
\hline Nationwide & 5 \\
\hline
\end{tabular}
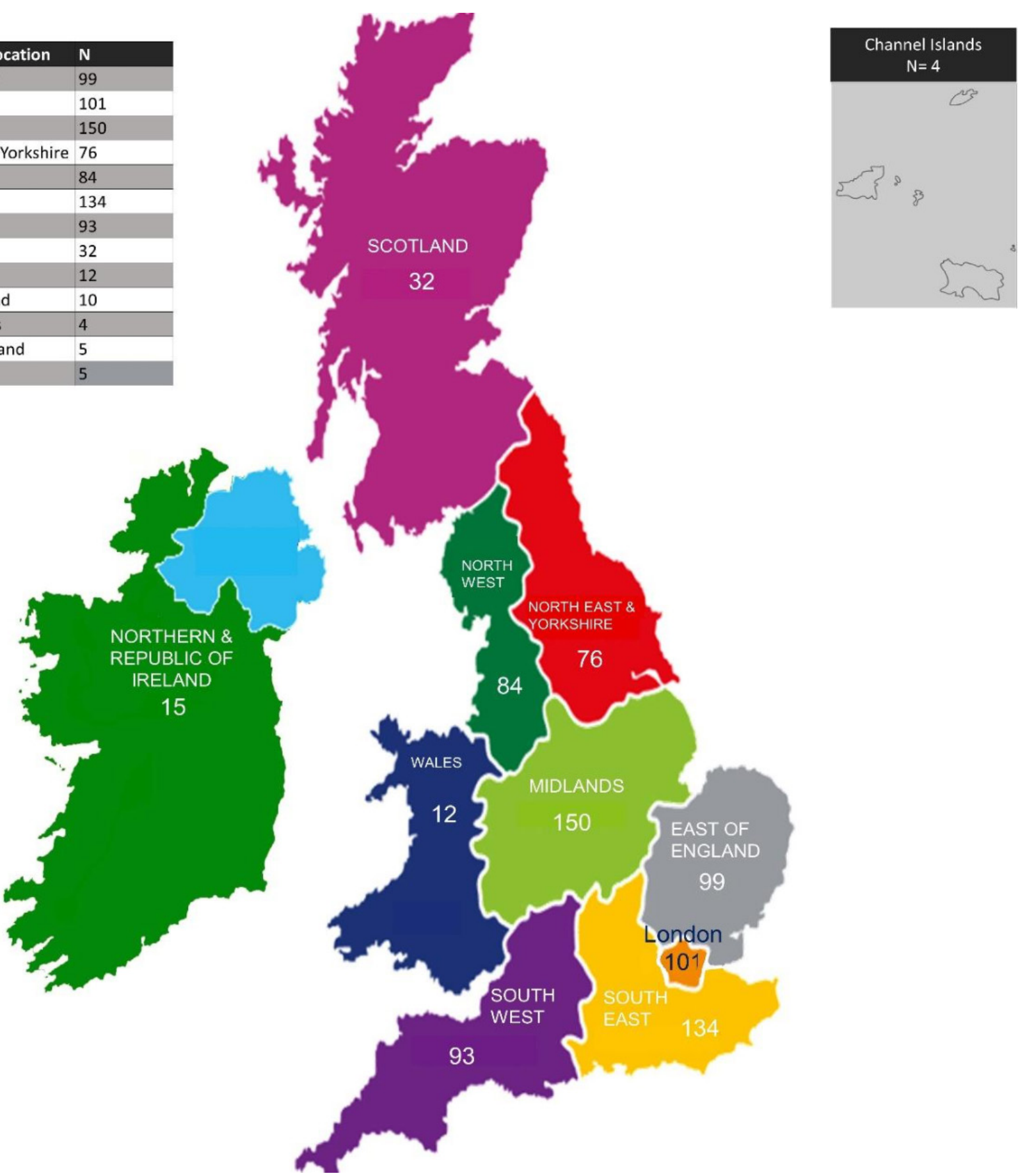

Figure 1 Geographical location.

additional ethical and privacy considerations of online and remote work.

However, these changes also served to increase opportunities for bereavement support. Whereas previous procedures had stipulated a waiting period before offering bereavement support or relied on self-referral, many were adopting a proactive approach due to heightened awareness of the bereaved relatives' need for support and increased social isolation following a death, whether from COVID-19 or from other causes: 'For families of patients who die in hospital, we are making contact sooner and by phone to 'debrief' in more detail'
(\#311 general practitioner). Services supporting children and young people at times reported these groups to have been more receptive to online support than usual methods.

Hospices and hospital teams reported widening access to their bereavement support to patients from across the local community or hospital, whereas this had previously only been available to relatives known to the services. Some of these wider services were specifically for those bereaved from COVID-19: 'We wouldn't normally deal with people that have been bereaved...we changed the service to meet the needs of those bereaved following 
Table 2 Bereavement care changes during COVID-19

\begin{tabular}{lllll}
\hline Changes to & Yes & No & Unsure & Illustrative comment examples \\
\hline $\begin{array}{l}\text { Use of telephone, } \\
\text { video or other } \\
\text { remote support }\end{array}$ & $(90 \%)$ & 52 & $22(3 \%)$ & $\begin{array}{l}\text { We were not using video call before covid and rarely offering counselling by phone, but this is } \\
\text { now primary to our service. (\#40 hospice bereavement service manager) }\end{array}$ \\
& & & $\begin{array}{l}\text { Learning about the different 'platforms' has needed energy to understand. New data protection } \\
\text { has also been needed in relation to information stored on phones. (\#293 community nurse) }\end{array}$
\end{tabular}
has also been needed in relation to information stored on phones. (\#293 community nurse)

It is more difficult picking up on subtleties of the consultation remotely, touch is obviously not possible either- everything is now done remotely for mental health in general practice. (\#444 general practitioner)

$\begin{array}{lll}\text { Supporting } & 586 & 157 \\ \text { people bereaved } & (76 \%) & (20 \%) \\ \text { from non-COVID } & & \end{array}$
from non-COVID conditions during the pandemic

$33(4 \%)$

Very challenging at first as we did not know how to support the bereaved as events were folding at a high and fast speed. Every case was treated as though it was Covid-19. Lots of gaps and lessons to be learned as some non-Covid patients were just classified as positive patients. (\#141 chaplain)

I have found families who have lost a member during the pandemic feel their loss is not as big as that of people dying of COVID. Or as important. (\#234 hospice social worker)

It is hard to differentiate between COVID and non-COVID deaths. The death may not be certified as COVID related, but the bereaved person experience may well be impacted by the COVID restrictions. (\#440 service manager/head of department)

$\begin{array}{lllrl}\text { Supporting people } & 500 & 189 & 85(11 \%) & \text { Sudden, more unexpected deaths, different bereavement response and reactions. Disbelief. } \\ \text { bereaved from } & (65 \%) & (24 \%) & \text { Practical questions about how long they should self-isolate for after the death if they visited the } \\ \text { COVID } & & & \text { hospital. (\#74 palliative medicine doctor) }\end{array}$

Visiting restrictions have meant much less face to face contact. For example I have talked with a spouse in the car park at social distance. (\#153 palliative medicine doctor)

There was a lot of anger about having Covid on the death certificate if they had been suffering from a long term illness prior. (\#572 hospice bereavement counsellor)

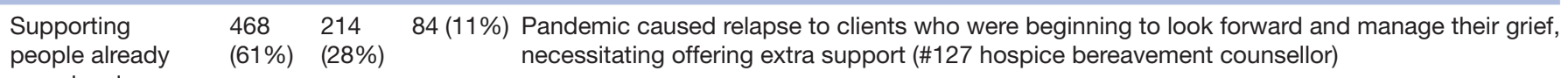

experiencing

bereavement when

the pandemic

started

Many clients receiving counselling have refused offers of telephone, preferring to wait until 'normal services resume'. (\#682 hospice social worker)

We are beginning to see more extreme reactions from people who were bereaved before the pandemic and who had begun to find ways of living in their altered world, but who now find that most of the outlets that they were using to help themselves are now closed to them. (\#271 hospice social worker)

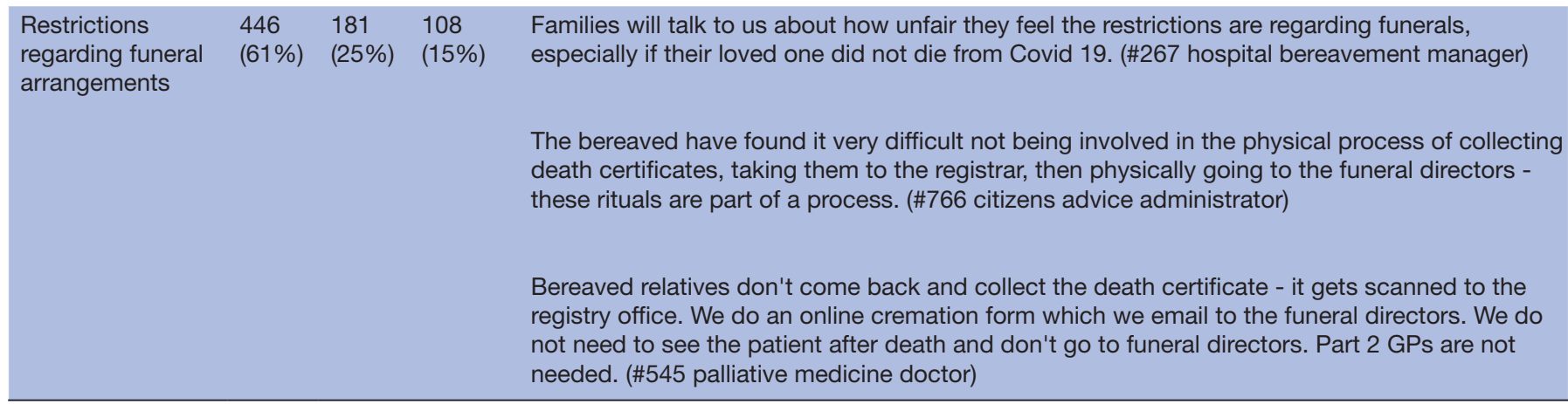

Continued 
Table 2 Continued

\begin{tabular}{|c|c|c|c|c|}
\hline Changes to & Yes & No & Unsure & Illustrative comment examples \\
\hline $\begin{array}{l}\text { Identifying } \\
\text { bereaved people }\end{array}$ & $\begin{array}{l}437 \\
(56 \%)\end{array}$ & $\begin{array}{l}291 \\
(37 \%)\end{array}$ & $59(7 \%)$ & $\begin{array}{l}\text { We've been unable to see as many family members face-to-face as we normally would, so it's } \\
\text { been harder for us to identify people. (\#58 hospice social worker) }\end{array}$ \\
\hline
\end{tabular}

who might need

support

More difficult to assess those who need support with distancing and limited visiting. This influenced our ability to form relationships with relatives and identify their needs. (\#104 palliative medicine doctor)

As a clinical team we were much more proactive, checking every bereaved family/carer and doing it twice and taking longer periods of time to make sure it was as right as it could be, impacting hours worked. (\#802 quality improvement lead)

$\begin{array}{lllll}\text { Managing complex } & 356 & 256 & 135 & \text { These are just more difficult cases to tackle, and the isolation - not having been able to visit a } \\ \text { forms of grief } & (48 \%) & (34 \%) & (18 \%) & \text { loved one in hospital who's subsequently died - exacerbates this. (\#7 general practitioner) }\end{array}$

We have at times entered territory/topics that are new and we do not have the answers to. (\#526 hospice family services manager)

Increase in referrals regarding this. (\#540 assistant psychologist)

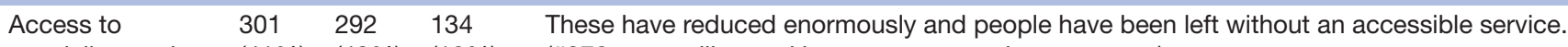
specialist services $\quad(41 \%) \quad(40 \%) \quad(18 \%) \quad$ (\#378 counselling and bereavement services manager)

for the bereaved

\begin{abstract}
Services like Cruse Bereavement Care have been so inundated that families do not get seen to as quickly as they normally would. Also, we usually advise that if families are struggling with their grief then they should visit their GP to get a referral to a counselling service, of course, GP's have been restricting appointments so this has become very challenging as to where we can sign post bereaved families to. (\#158 medical examiners officer)
\end{abstract}

Limited access as specialist services such as psychological support staff were redeployed. (\#104 palliative medicine doctor)

a COVID-19 death' (\#483 palliative care day services manager).

Collaborative efforts were described, bringing together local agencies such as hospices, district hospitals and charities. New services had been developed, often telephone helplines or online support that would offer compassionate support and information on local and national services. Other innovations included allowing families to email pictures to place in patients' rooms, providing bereaved families with mementos such as knitted hearts, sending condolence cards and arranging for the return of the deceased's property. Some of these service adaptations, particularly online support, were reported to be long-term changes.

Many respondents also reported a lower rate of uptake from bereaved people than they had anticipated in the initial stages of the pandemic, although more recently referrals had increased and were expected to increase further. Some feared being overwhelmed by demand: We are really only seeing those who have been bereaved in Jan/Feb so far, so there may be many more to come' (\#129 community listening service coordinator).
The impact on clinicians and their relationships with bereaved relatives

Changes to services impacted on how practitioners interacted with and built relationships with bereaved people. The reduced ability to meet face-to-face was repeatedly raised and reported to impact on all stages of a bereaved person's journey.

Restrictions on visiting meant practitioners had less, or no, opportunities to see family members before the death to assess their potential bereavement support needs. Following the death, collection of death certificates, visits to registry offices and appointments with funeral directors were all arranged online or by telephone: these had previously been ways for bereaved families to meet professionals, ask questions and discuss the death: 'Family would come back to the unit to collect the death certificate face to face the following day which allows time to sit and talk to them about their needs, and this no longer happens' (\#111 palliative medicine doctor).

Emotional support was reported to have been significantly disrupted. Physical distancing, the use of personal protective equipment (PPE) and use of remote support were restricting non-verbal communication such as facial expressions and body language which were felt to be 
Table 3 Impacts of the pandemic on bereavement care practice

$\begin{array}{ll}\text { Theme } & \text { Illustrative quotes } \\ \begin{array}{l}\text { 1. Impact on } \\ \text { services }\end{array} & \begin{array}{l}\text { Before COVID there needed to be an improvement in specialist bereavement services. The generic support } \\ \text { provided by staff has become more difficult to provide - particularly during the height of COVID in the } \\ \text { community setting when only essential visits were being done face to face. There still needs to be better } \\ \text { access to bereavement services. Furthermore, there is no access to chaplaincy in the community setting } \\ \text { which should be considered. (\#582 palliative medicine doctor) } \\ \text { As team leader of a small team of nurses providing a Hospice at Home service countywide. Prior to COVID } \\ \text { - } 19 \text { we had already identified there is a gap in follow up bereavement support for families of the patients } \\ \text { who we have nursed. It is not something we have the capacity to do. (\#670 community nurse) } \\ \text { The staff adapted very professionally and quickly to ensure there were no gaps in sessions for those needing } \\ \text { the service... We did have to write a whole new service protocol and generate new confidentiality statements } \\ \text { and counselling contracts as the staff working with online platforms had to set out new boundaries for } \\ \text { counselling and support, having looked into these boundaries, it was a bit scary at first because you have to } \\ \text { protect the staff who can see into people homes and personal space and ensure there are no interruptions } \\ \text { during the session with IT breaking down etc. However, now } 5 \text { months on from lockdown, we do find that the } \\ \text { challenges and most clients engage well. (\#475 head of information and supportive care services) }\end{array}\end{array}$

2. Impact on clinicians and relationships with patients
It has brought many challenges for both client and counsellor. Much of what happens in the counselling session is about reading body language and facial expressions. This has proven nearly impossible. Also it is much more difficult to build an empathic trusting relationship when there is a phone or computer in between client and counsellor. It has been harder to reach young bereaved people as not always appropriate to do telephone or video work. (\#554 hospice bereavement counsellor)

I found it really, really emotionally taxing. It is not in my normal day job to be having conversations. I found preparing patients and relatives for intubating knowing that may be the beginning of their grief journey incredibly hard. (\#407 respiratory physiotherapist)

This has been a difficult time for both the bereaved and staff. The bereaved have a reduced, non face to face service. The staff feel powerless and are restricted from doing the job they are passionate about. That said a great deal of learning has been going on and staff have been imaginative in finding new approaches. (\#418 palliative care specialist nurse)

3. Impact on I feel it's the isolation that is causing the greatest emotional and mental anguish. That, and the fact that many bereaved people people saw their loved ones poorly at home, then taken to hospital, never to be seen again. This leaves very deep scars. So I feel peer support is fundamental to help bereaved families feel and share their story with others and, have a chance to hear someone's else story. Grief is unique to every individual but community spirit helps heal, through a sense of belonging and walking with people who understand your pain. (\#617 bereavement support worker/volunteer)

The experience of grief is far more complex given majority of loved ones have been mostly separated from the dying person during the illness and even during most of the dying process... Families have experienced more complex guilt for feeling somehow they may have failed in their duty to shield vulnerable loved ones from the infection or that they couldn't be united with their loved ones during the illness (\#215 general practitioner)

I have concerns that some bereavements may be more complex due to visiting restrictions - families may not have been able to say goodbye as they wished or had less time with their loved one. Some have changed their preferred place of death based on visiting restrictions. Some people dislike virtual support and prefer face to face, so it is likely that despite efforts, bereavement support has not been as high quality as it was. (\#690 palliative care doctor) important in developing trusting relationships: 'The use of staff PPE has made communication more complex, limiting non-verbal communication and making staff and families feel uncomfortable' (\#368 clinical psychologist).

It has felt as though we are dealing with them at arm's length whereas we would be there to hold their hands, give them a hug as needed. (\#16 palliative medicine doctor)

Associated with this sense of moral injury were reports of a broader emotional impact on practitioners who described finding remote support more demanding on emotional reserves and attention. Conversations were described as more difficult as practitioners had been unable to develop relationships with families, and the bereaved needed more information and support as they had been unable to visit and see how their family member changed over time: 'It relies on clinicians to paint a visual picture of what is happening, which is a new skill and also relies on clinicians taking the time to have these conversations' (\#117 palliative medicine doctor). Respondents described such work as 'draining' and difficult to manage, alongside their own emotional strains during the pandemic, including their own experiences of loss and feelings of grief. 


\section{The impact on bereaved people}

Many respondents expressed grave concerns over the long-term impacts on bereaved people, highlighting the inability or restrictions on being with the dying patient as having a profound impact in bereavement. Family members were reported to feel guilty that they had not been able to be with the dying person and say 'goodbye', and frustrated that they had been unable to ensure their loved one's wishes were respected at the end of life:

Many people who died were denied opportunity to die in their preferred place of care/preferred place of death and died in alternative makeshift community hospital environments that were less than person centred and suboptimal environments to receive their care in last days. (\#215 general practitioner)

Not being able to 'see the journey' of the dying patient meant bereaved families often had questions following a death, with reports of increased queries from family members about the care received, including anger at restrictions and feelings of unfairness, leading to difficulties in accepting the death: 'Families feel cheated and robbed of a relative who normally would be still alive if not for the virus' (\#234 social worker).

Restrictions around returning the deceased person's belongings and viewing the body, particularly for patients with COVID-19 and restricted funeral arrangements were reported to have caused significant distress and exacerbated feelings of unfairness.

While those bereaved from COVID-19 and nonCOVID-19 conditions were similarly affected by the restrictions, specific challenges related to COVID-19 were reported. Some respondents described relatives' anger at having COVID-19 on the death certificate, commenting that the disease 'seemed to have a 'stigma' for some' (\#233 bereavement specialist liaison nurse). This sense of stigma was thought to exacerbate peoples' feelings of having failed to protect their family member from COVID-19.

Respondents suggested that the focus on COVID-19 deaths had adversely impacted on the bereavement experiences of those whose loved one had died of other conditions who may 'feel their loss is not as big as that of people dying of COVID. Or as important' (\#234 hospice social worker). In some cases, funding was allocated only for those who had been bereaved by COVID-19, which 'could create inequality of service provision' (\#40 hospice bereavement service manager).

Those bereaved prior to the pandemic were also impacted. Some were reported to find it difficult to move from face-to-face to online support and preferred to wait until in-person support would resume. Lockdown restrictions were described as a 'second bereavement' (\#776 bereavement support coordinator) as historic bereavements resurfaced during the pandemic leading to increased demand for services. An overall climate of increased loneliness, social isolation, fear and anxiety among communities was perceived to be heightening existing mental health difficulties related to bereavement.
Respondents reported many unknown impacts of the pandemic on bereaved people and how these would be managed when services "were already patchy and not fit for purpose prior to the COVID-19 pandemic' (\#9 palliative medicine doctor). Concerns were raised over a large and 'invisible cohort of people' (\#611 palliative medicine doctor) who may not access support or for whom support will be restricted, leading to greater unmet need: There may be a silent epidemic of grief that we have not yet picked up on' (\#9 palliative medicine doctor).

\section{DISCUSSION}

Evidence on the impact of the COVID-19 pandemic on the experience of bereavement is emerging. This study of UK bereavement care practice during the pandemic reveals significant changes in the delivery of support and the ways in which services have adapted to address the more complex needs of bereaved families. Bereavement care has undergone major change in both acute and community settings affecting bereaved people, clinicians, support workers, and the wider health and social care system. Increased need for bereavement care has challenged practitioners as they have taken on new responsibilities and skills, and shifted to remote and electronic working. The potential for prolonged and complicated grief responses is particularly concerning. ${ }^{19} 20$

The large number of replies from across the UK and Ireland and the wide range of professional roles and settings represented support the potential generalisability of the data. Anonymity encouraged detailed and honest responses. However, due to snowball sampling it is not possible to calculate a response rate or appraise the representativeness of the sample. While there was consistency in responses across settings, further research is needed to investigate the settings and bereaved populations where support needs are highest. The survey instrument was selfdeveloped as a rapid response to understand the impact of the pandemic on bereavement services and was not subjected to psychometric testing.

As the world navigates the ongoing challenges of the pandemic, urgent consideration is needed of ways to ensure optimal support: bereavement can have a significant impact on morbidity and mortality, yet bereavement care often remains an afterthought in clinical priorities. ${ }^{21}$ This study highlights that bereavement care is a significant component of health and social care across a wide range of settings and clinical roles although practitioners may at times feel poorly equipped to manage bereavement. ${ }^{22-24}$

Practitioners indicated remote delivery of some bereavement support may be implemented long term; however, further research on the efficacy of remote support for bereavement is required. Trusting relationships and compassionate communication between staff and bereaved families are critical to bereavement care. ${ }^{25}$ This is challenging to ensure through remote and online routes, creating additional burdens of time and emotional resources for an already overstretched and exhausted workforce. The 
Box 1 Implications for bereavement care practice and policy

- Improved resources for existing bereavement services to enable coordination between local, regional and national networks, and encourage a sustainable model of bereavement care.

- Developing a proactive approach to supporting those bereaved during this period and making services accessible for all.

- Enabling regular communication with families prior to a death and after to ensure families have opportunities to ask questions and receive reassurance.

- Where possible, find ways for families to be with dying loved ones.

- Integrating assessment of bereaved families' needs into communication to help identify and signpost those who might require further support.

- Training in bereavement care to be integrated into medical, nursing and other healthcare professional training.

- Acknowledging the challenges on staff and encourage brief training for those who feel unequipped to manage needs of grieving families.

emotional and personal impact on practitioners highlighted in this study is a particular area of concern. ${ }^{2627}$

Bereavement service provision has for many years been highly variable across the UK. ${ }^{28}$ While it was heartening that many respondents reported the development of new and expanded services, it is unclear how sustainable these will be in the longer term. The markedly reduced income of many charities during the pandemic is concerning for future provision of bereavement and palliative care. ${ }^{29}$ Given the increasing need for bereavement support highlighted during the pandemic, it is imperative that policymakers, funders, health, social care and community services work together to develop a sustainable model of resourcing at local, regional and national levels.

In the early stages of the pandemic, physical health needs were understandably prioritised. However, there is now a need to also focus on the mental health needs of the population, including the needs of the many people bereaved over the course of the ongoing pandemic. Respondents indicated a high level of unmet support needs of bereaved people, with concerns of subsequent significant physical and psychological morbidity. Service adaptations reported in this study propose the potential benefits of a proactive approach during this period, offering support for all those bereaved whether from COVID-19 or other conditions ${ }^{615}$ (see box 1 Implications for bereavement care practice and policy).

To address the potential 'silent epidemic of grief', it is also important to build public awareness of the availability and accessibility of bereavement support services to encourage bereaved people to view grief as a 'valid' reason to seek help from health and community services. ${ }^{30}$ While many bereaved people adjust to their loss with informal support of family, friends and community, the three-tiered "public health model of bereavement support' may help to guide professionals to identify those who need support from services and those at risk of complicated and prolonged grief responses. ${ }^{32}$
This study highlights the profound impact of the pandemic on bereaved people, yet much remains unknown about how individuals, communities, and the health and social care system will respond. While further research is urgently needed in this area, we already know that action is needed now to ensure equity of provision across ethnic groups, ages and marginalised groups, and equity of care for all bereaved people whether from COVID-19, from other conditions or those bereaved prior to the pandemic.

\section{CONCLUSION}

Bereavement care is a central aspect of the work of a wide range of health and social care professionals yet remains a low priority within healthcare policy. The COVID-19 pandemic has highlighted this important area of patient care, creating both major challenges to bereavement support provision and opportunities for practitioners and policymakers to address this neglected aspect of clinical care. Bereavement is one of the long-term impacts of COVID-19: if left unaddressed it may lead to significant physical and mental health morbidity and create a further burden on health and social care services.

Acknowledgements We would like to thank Revd Dr Derek Fraser for providing expert advice and supporting the dissemination of this survey. We would like to thank Angela Harper for her essential administrative support on this project. Additionally, we extend our thanks to all the organisations who assisted in the circulation of this survey.

Contributors $\mathrm{CP}$ and SB designed and co-led the study. RL, MS, NZC, CH and AL contributed to the study design. $\mathrm{CP}, \mathrm{JRH}$ and $\mathrm{SB}$ conducted the data analysis. $\mathrm{CP}$, JRH and SB drafted the paper. All the authors reviewed and commented on the draft paper and have approved this final version. $\mathrm{CP}$ and $\mathrm{SB}$ are the guarantors.

Funding This study was funded by the NIHR School for Primary Care Research (grant reference no: 468). SB is also part funded by the National Institute for Health Research (NIHR) Applied Research Collaboration East of England (ARC EoE) programme (grant reference: $n / a)$.

Disclaimer The views expressed are those of the author(s) and not necessarily those of the NIHR, the NHS or the Department of Health and Social Care.

Map disclaimer The depiction of boundaries on the map(s) in this article does not imply the expression of any opinion whatsoever on the part of BMJ (or any member of its group) concerning the legal status of any country, territory, jurisdiction or area or of its authorities. The map(s) are provided without any warranty of any kind, either express or implied.

Competing interests None declared.

Patient consent for publication Not required.

Ethics approval The study was reviewed by the University of Cambridge Psychology Research Ethics Committee (PRE.2020.094).

Provenance and peer review Not commissioned; externally peer reviewed.

Data availability statement Anonymised data are available upon reasonable request.

Supplemental material This content has been supplied by the author(s). It has not been vetted by BMJ Publishing Group Limited (BMJ) and may not have been peer-reviewed. Any opinions or recommendations discussed are solely those of the author(s) and are not endorsed by BMJ. BMJ disclaims all liability and responsibility arising from any reliance placed on the content. Where the content includes any translated material, BMJ does not warrant the accuracy and reliability of the translations (including but not limited to local regulations, clinical guidelines, terminology, drug names and drug dosages), and is not responsible for any error and/or omissions arising from translation and adaptation or otherwise.

Open access This is an open access article distributed in accordance with the Creative Commons Attribution Non Commercial (CC BY-NC 4.0) license, which 
permits others to distribute, remix, adapt, build upon this work non-commercially, and license their derivative works on different terms, provided the original work is properly cited, appropriate credit is given, any changes made indicated, and the use is non-commercial. See: http://creativecommons.org/licenses/by-nc/4.0/.

\section{ORCID iD}

Caroline Pearce http://orcid.org/0000-0003-4653-2697

\section{REFERENCES}

1 Verdery AM, Smith-Greenaway E, Margolis R, et al. Tracking the reach of COVID-19 kin loss with a bereavement multiplier applied to the United States. Proc Natl Acad Sci U S A 2020;117:17695-701.

2 Boelen PA, Smid GE. Disturbed grief: prolonged grief disorder and persistent complex bereavement disorder. BMJ 2017;357:j2016.

3 Gesi C, Carmassi C, Cerveri G, et al. Complicated grief: what to expect after the coronavirus pandemic. Front Psychiatry 2020;11:489.

4 Kokou-Kpolou CK, Fernández-Alcántara M, Cénat JM. Prolonged grief related to COVID-19 deaths: do we have to fear a steep rise in traumatic and disenfranchised griefs? Psychol Trauma 2020;12:S94-5.

5 Kentish-Barnes N, Chaize M, Seegers V, et al. Complicated grief after death of a relative in the intensive care unit. Eur Respir $J$ 2015;45:1341-52.

6 Selman LE, Chao D, Sowden R, et al. Bereavement support on the frontline of COVID-19: recommendations for hospital clinicians. $J$ Pain Symptom Manage 2020;60:e81-6.

7 Wallace CL, Wladkowski SP, Gibson A, et al. Grief during the COVID-19 pandemic: considerations for palliative care providers. $J$ Pain Symptom Manage 2020;60:e70-6.

8 Eisma MC, Tamminga A, Smid GE, et al. Acute grief after deaths due to COVID-19, natural causes and unnatural causes: an empirical comparison. J Affect Disord 2021;278:54-6.

9 Petter O. Man. 75, puts poster in window asking for friends after wife's sudden death. The Independent, 15 September 2020. Available: https://www.independent.co.uk/life-style/lonely-manfriend-grief-death-age-b446075.html [Accessed 18 Feb 2021].

10 Guldin M-B. Managing bereavement during the COVID-19 pandemic: European association for palliative care blog, 2020. Available: https:// eapcnet.wordpress.com/2020/04/14/managing-bereavement-duringthe-covid-19-pandemic/

11 Mayland CR, Harding AJE, Preston N, et al. Supporting adults bereaved through COVID-19: a rapid review of the impact of previous pandemics on grief and bereavement. J Pain Symptom Manage 2020;60:e33-9.

12 Yardley S, Rolph M. Death and dying during the pandemic. BMJ 2020;369:m1472.

13 O'Mahony S. Mourning our dead in the covid-19 pandemic. BMJ 2020;369:m1649.

14 Burrell A, Selman LE. How do Funeral practices impact bereaved relatives' mental health, grief and bereavement? a mixed methods review with implications for COVID-19. Omega 2020:003022282094129.
15 Harrop E, Mann M, Semedo L, et al. What elements of a systems' approach to bereavement are most effective in times of mass bereavement? A narrative systematic review with lessons for COVID-19. Palliat Med 2020;34:1165-81.

16 Boelen PA, Eisma MC, Smid GE, et al. Remotely delivered cognitive behavior therapy for disturbed grief during the COVID-19 crisis: challenges and opportunities. Journal of Loss and Trauma 2020;45:1-9.

17 Eysenbach G. Improving the quality of web surveys: the checklist for reporting results of Internet E-Surveys (cherries). J Med Internet Res 2004;6:e34

18 Pope C, Ziebland S, Mays N. Analysing qualitative data. BMJ 2000;320:114.

19 Carr D, Boerner K, Moorman S. Bereavement in the time of coronavirus: unprecedented challenges demand novel interventions. J Aging Soc Policy 2020;32:425-31.

20 Morris SE, Moment A, Thomas JdeLima, Thomas JD. Caring for bereaved family members during the COVID-19 pandemic: before and after the death of a patient. J Pain Symptom Manage 2020;60:e70-4.

21 Aoun SM. Bereavement support: from the poor cousin of palliative care to a core asset of compassionate communities. Prog Palliat Care 2020;28:107-14

22 Morris S, Schaefer K, Rosowsky E. Primary care for the elderly bereaved: recommendations for medical education. J Clin Psychol Med Settings 2018;25:463-70.

23 O'Connor M, Breen LJ. General Practitioners' experiences of bereavement care and their educational support needs: a qualitative study. BMC Med Educ 2014;14:10.

24 Naef R, Peng-Keller S, Rettke H, et al. Hospital-Based bereavement care provision: a cross-sectional survey with health professionals. Palliat Med 2020;34:547-52.

25 Heath I. COVID-19 and the legacy of grief. Br J Gen Pract 2020;70:428.

26 Lichtenthal WG, Roberts KE, Prigerson HG. Bereavement care in the wake of COVID-19: offering Condolences and referrals. Ann Intern Med 2020;173:833-5.

27 Greenberg N, Docherty M, Gnanapragasam S, et al. Managing mental health challenges faced by healthcare workers during covid-19 pandemic. BMJ 2020;368:m1211.

28 Hewison A, Zafar S, Efstathiou N. Bereavement support in the UK - a rapid evidence assessment. Birmingham: Sue Ryder/University of Birmingham, 2019.

29 Mahase E. Covid-19: charity cuts could put the NHS under even more pressure. BMJ 2020;370:m3261.

30 Harrop E, Morgan F, Longo M, et al. The impacts and effectiveness of support for people bereaved through advanced illness: a systematic review and thematic synthesis. Palliat Med 2020;34:871-88.

31 Feigelman W, Sanford RL, Cerel J. Do primary care physicians help the bereaved with their suicide losses: loss survivor perceptions of Helpfulness from physicians. Omega 2020;80:476-89.

32 Aoun SM, Breen LJ, White I, et al. What sources of bereavement support are perceived helpful by bereaved people and why? empirical evidence for the compassionate communities approach. Palliat Med 2018;32:1378-88. 